\title{
Cytomegalovirus retinitis presenting as vasculitis in a patient with Wegener's granulomatosis
}

\author{
Paris G Tranos' \\ Ilias Georgalas ${ }^{2}$ \\ Panagiota Founti \\ loannis Ladas ${ }^{2}$ \\ 'Papageorgiou University Hospital, \\ Thessaloniki, Greece; 'Department \\ of Ophthalmology, "G.Genimatas" \\ Hospital, Athens, Greece
}

\begin{abstract}
Purpose: To present an unusual case of cytomegalovirus (CMV) retinitis in a patient with Wegener's granulomatosis.

Results: A 54-year-old lady with Wegener's granulomatosis presented with decreased vision in her left eye. Wegener's retinal vasculitis was diagnosed initially and the patient received treatment with oral steroids. Three days later the patient developed typical CMV retinitis.

Conclusion: The likelihood of CMV retinitis in patients with Wegener's granulomatosis should not be overlooked. Increased awareness in such cases is very important since CMV retinitis may present with less typical manifestations, which makes the correct diagnosis more challenging. Keywords: cytomegalovirus retinitis, Wegener's granulomatosis, ganciclovir
\end{abstract}

\section{Introduction}

Cytomegalovirus (CMV) is the main cause of infectious retinitis in severely immunosuppressed hosts (Pertel et al 1992). Wegener's granulomatosis is an immunemediated disorder with frequent eye involvement. CMV retinitis is extremely uncommon in these patients and it may present with atypical characteristics posing diagnostic dilemmas.

We present a case of CMV retinitis in a patient with Wegener's granulomatosis which was diagnosed and treated initially as Wegener's retinal vasculitis.

\section{Case report}

A 54-year-old female patient presented at the Ophthalmic clinic complaining of mild eye discomfort and gradual reduction of vision in her left eye over the previous 10 days. The patient had a history of meningitis in the past and surgery for removal of pituitary adenoma 13 years ago. Four years earlier she developed central nervous system vasculitis and was diagnosed with Wegener's granulomatosis. At presentation the patient was immunosuppressed due to her treatment with methylprednizolone $5 \mathrm{mgr} /$ day and cyclophosphamide $1.5 \mathrm{mgr} / \mathrm{kg} /$ day.

On examination her best corrected visual acuity (BCVA) in the symptomatic left eye was 6/9-2. Blood tests and chest X-ray excluded other inflammatory conditions, however, CD-4 levels was $180 / \mathrm{mm}^{3}$. There was no activity from the anterior chamber, however, there was mild vitritis. B-mode ultrasound excluded scleritis with normal scleral thickness and fundoscopy revealed vasculitis and a few cotton wool spots in the peripapillary area and along the vascular arcades sparing the macula. At that time her clinical picture was consistent with Wegener's retinal vasculitis and her oral prednisolone was increased to $60 \mathrm{mgr} /$ day $(1 \mathrm{mg} / \mathrm{Kg})$. Further deterioration in her BCVA was noted when the patient was reviewed 3 days later. Fundus examination revealed moderate to severe vitritis ,retinitis and development of typical "pizza-pie" appearance of CMV retinitis was noted (Figure 1). The right eye was uninvolved. 


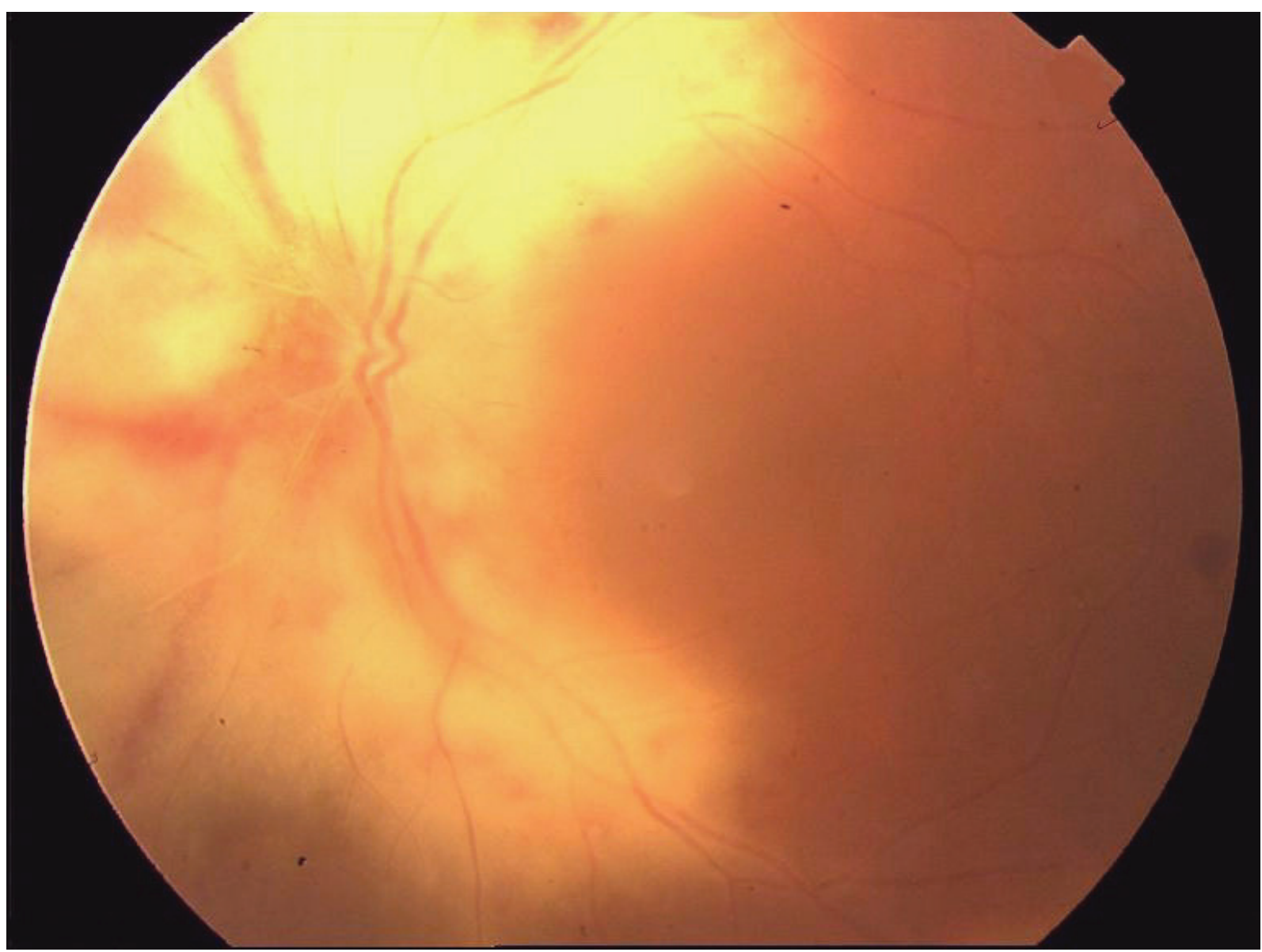

Figure I Color photograph showing retinitis with scatter retinal hemorrhages in the peripapillary area and along the vascular arcades. Fundal details appear blurred due to coexisting vitritis.

Based on the clinical manifestations, the patient was initiated on intravenous gancyclovir $5 \mathrm{mg} / \mathrm{kg}$ twice a day.

Ten days later there was no further progression of retinitis and vitritis was minimal. Subsequently the first signs of improvement were apparent, with regression of exudates, reduction of retinal hemorrhages and development of retinal pigment epithelial changes. Gancyclovir was reduced to $5 \mathrm{mgr} / \mathrm{kgr}$ once a day and it was discontinued two months following complete regression of CMV retinitis (Figure 2).

Four months later, in the last follow-up examination, the patient's vision remained stable at presentation levels.

\section{Discussion}

Ocular disease occurs in $29 \%$ to $58 \%$ of patients with Wegener's granulomatosis. The three main categories of ocular involvement are scleritis with or without peripheral keratitis, orbital disease, and vasculitis-mediated vascular complications (Haynes et al 1977; Hoffman et al 1992).

With the advent of corticosteroid and especially cytotoxic drugs, which altered the outlook for the disease, the prognosis of Wegener's granulomatosis has improved considerably. However, the use of immunomodulators may be associated with several systemic adverse effects and since the patients' immune system is compromised there is a potentially increased risk of opportunistic infections.

Interestingly, CMV retinitis is extremely rare when associated with Wegener's granulomatosis (Nicholson 1975; Riordan-Eva et al 1993; Tanihar et al 1993; Tugal-Tutkun et al 2000; Bertelmann et al 2005). In the case described above the minimal signs of retinitis and the minimal amount of vitritis, on presentation lead to the diagnosis of Wegener's vasculitis. Wegener's granulomatosis is always related to arteritis while CMV retinitis, which more frequently starts from the periphery, is related to vasculitis. Interestingly, in our case, infection was started from the posterior pole involving the optic disc and the peripappilary area.

This case points out that the possibility of CMV retinitis, although very rare, should not be overlooked in patients with Wegener's granulomatosis. Increased awareness in these patients is very important especially if we consider that CMV 


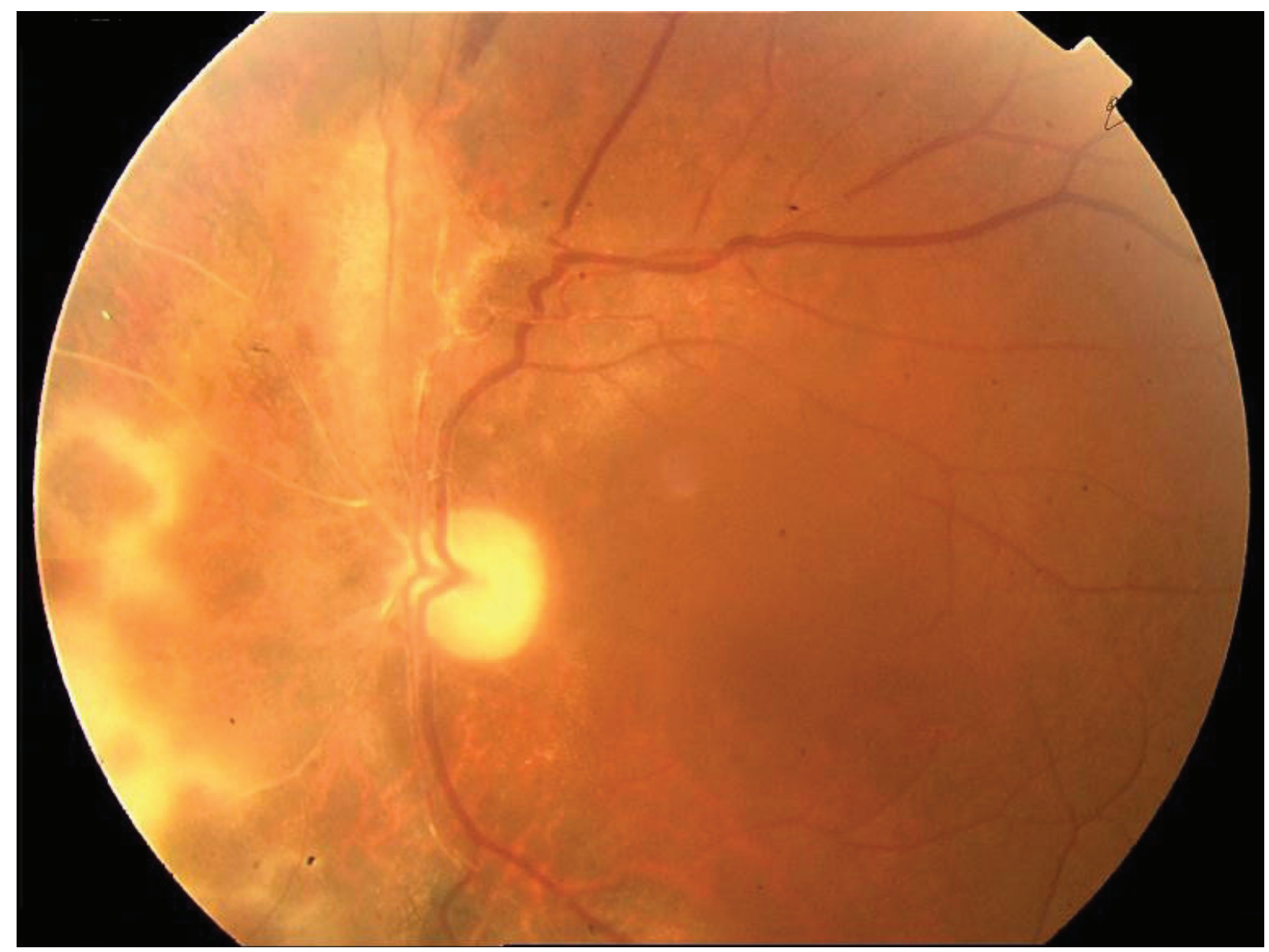

Figure 2 Regression of retinitis following treatment with ganciclovir, leaving retinal pigment epithelial changes and pale optic disc.

retinitis may present with less typical manifestations making the correct diagnosis more challenging. Prompt treatment with administration of antiviral agents is mandatory for the arrest of retinitis progression, earlier rehabilitation and prevention of more sinister complications.

\section{Disclosure}

The authors report no conflicts of interest in this work.

\section{References}

Bertelmann E, Liekfeld A, Pleyer U, et al. 2005. Cytomegalovirus retinitis in Wegener's granulomatosis: case report and review of the literature. Acta Ophthalmol Scand, 83:258-61.

Haynes BF, Fishman ML, Fauci AS, et al. 1977. The ocular manifestations of Wegener's granulomatosis. Fifteen years experience and review of the literature. Am J Med, 63:131-41.
Hoffman GS, Kerr GS, Leavitt RY, et al. 1992. Wegener granulomatosis: an analysis of 158 patients. Ann Intern Med, 116:488-98.

Nicholson DH. 1975. Cytomegalovirus infection of the retina. Int Ophthalmol Clin, 15:151-62.

Pertel P, Hirschtick R, Phair J, et al. 1992. Risk of developing cytomegalovirus retinitis in persons infected with the human immunodeficiency virus. J Acquir Immune Defic Syndr, 5:1069-74.

Riordan-Eva P, Williams CE, Wing AJ, et al. 1993. Retinal neovascularization secondary to cytomegalovirus retinitis in Wegener's granulomatosis. $J$ R Soc Med, 86:301-2.

Tanihara H, Nakayama Y, Honda Y, et al. 1993. Wegener's granulomatosis with rapidly progressive retinitis and anterior uveitis. Acta Ophthalmol (Copenh), 71:853-5.

Tugal-Tutkun I, Kir N, Gül A, et al. 2000. Cytomegalovirus retinitis in a patient with Wegener's granulomatosis. Ophthalmologica, 214:149-52. 
